extreme accuracy is not required or where accuracy cannot be obtained in any event because of errors introduced by other steps in the analytical procedure. However, it is always desirable to improve the accuracy of a convenient method, and this can some. times be done when sources of inaccuracy are known. For this reason I welcome Dijkstra's critical comment on the method for estimation of peak areas.

$$
\text { K. K. Carroll }
$$

Collip Medical Research Laboratory,

University of Western Ontario, London, Ontario.

\section{Behaviour of $5 A$ Molecular Sieve in Subtractive Gas Chromatography}

$5 A$ molecular sieve can be used to remove selectively normal paraffins from hydrocarbon samples in the gas phase at the inlet of a gas liquid chromatographic column ${ }^{1,2}$. This subtraction technique has formed the basis of analytical procedures for the determina. tion of the normal paraffins in complex petroleum fractions and has been applied in conjunction with both packed and capillary columns ${ }^{3}$.

It has also been shown that at high temperatures (c. $300^{\circ} \mathrm{C}$.) normal paraffins could be removed in a similar manner from waxes but in this molecular weight-range only 2-methyl eicosane and the highly branched paraffin squalane were available to test the selectivity of the molecular sieve. Neither of these compounds was sorbed by the sieve at a temperature of $320^{\circ} \mathrm{C}$

Recently, Murray et al.$^{4}$ have reported that unspecified single methyl branched paraffins in the wax range are completely removed from the gas phase by $5 A$ sieve. This affinity for the singly branched paraffins was destroyed by repeated passage of these compounds through the sieve until no further sorption occurred. However, the sieve was still capable of retaining the normal paraffins.

We have now studied the behaviour of the single methyl branched hydrocarbons in greater detail using in particular a sample of 2-methyl dotriacontane synthesized in our laboratories ${ }^{5}$. In these experiments a pre-column $6 \mathrm{~cm}$. long and $6 \mathrm{~mm}$. internal diameter was packed with activated 30-60 B.S. mesh $5 \mathrm{~A}$ molecular sieve. This pre-column was attached to the inlet of an $86-\mathrm{cm}$. gas-liquid chromatography column, also of $6 \mathrm{~mm}$. diameter, containing 26 per cent wt. of silicone grease $E .301$ on $52-60$ B.S. mesh 'Sil-O-Cel' firebrick. The pre-column was maintained at $320^{\circ} \mathrm{C}$. and the gas-liquid chromatography column at $296^{\circ} \mathrm{C}$. These conditions had been used previously for wax separations and were known to be satisfactory for such mixtures ${ }^{3}$. $10-\mu l$ samples of pure paraffin hydrocarbons were introduced into the precolumn and their behaviour is shown in Table 1.

At $\mathrm{C}_{33}$ the 2-methyl paraffin is completely sorbed whereas at $\mathrm{C}_{24}$ and below this type of compound is not

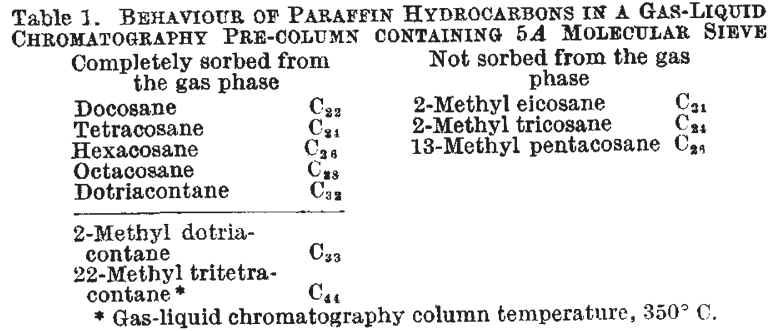

sorbed by the sieve. Also, when the branching occurs in the middle of the molecule the $\mathrm{C}_{44}$-branched paraffin is retained, but the similar $\mathrm{C}_{26}$ compound is not sorbed. At some critical chain-length between the limits indicated, single methyl branched paraffins start to be sorbed by the $5 A$ sieve.

Further work on the selectivity of the sieve will be carried out as more reference hydrocarbons in this range become available.

We wish to thank Mrs. M. Colwell for the synthesis of some of the paraffins used in the work.

\section{F. R. AdTARD}

B. T. WHITHAM

'Shell' Research Ltd.,

Thornton Research Centre,

$$
\text { P.O. Box 1, }
$$$$
\text { Chester. }
$$

'Brenner, N., and Coates, V. J., Nature, 181, 1401 (1958).

${ }^{2}$ Whitham, B. T., Nature, 182, 391 (1958).

${ }^{3}$ Adlard, E. R., and Whitham, B. T., Reprints, Intern. Gas Chromatography Symp. (Instrum. Soc. Amer, 1961).

'Downing, D. T., Kranz, Z. H., and Murray, K. E., Austral. J. Chem. $13(1), 80(1960)$

${ }^{5}$ Colwell, M. (to be published).

\section{Improved Gas Chromatography of Unesterified Fatty Acids}

Is has been demonstrated by Böttcher et al. ${ }^{1}$ and by Hunter et al. ${ }^{2}$ that unesterified fatty acids can be separated, by gas chromatography, by the use of 'liquid' phases of the polyester type. Metcalfe ${ }^{3}$ has pointed out the necessity to have a highly acidic 'liquid' phase in order to suppress the association of the carboxyl group of the fatty acids, and has shown that the separation of $\mathrm{C}_{4}-\mathrm{C}_{22}$ fatty acids is very much improved by the incorporation of phosphoric acid in the polyester 'liquid' phase. Using a column packing of 'Celite 545' previously coated with 25 per cent of diethylene glycol adipate polyester and 2 per cent of phosphoric acid, mixtures of fatty acids were separated at temperatures of $220-235^{\circ} \mathrm{C}$., yielding welldefined symmetrical peaks and separating saturated and unsaturated acids from each other.

The development of the argon ionization detector has resulted in higher sensitivities of detection, allowing a reduction of sample size. This reduction of sample size itself improves column efficiency and, in addition, allows the use of columns with lower content of 'liquid' phase, which in turn leads to improved. resolution and a faster analysis. A faster analysis is particularly important with the separation of fatty acids which are more thermo-labile than their corresponding methyl esters. However, the choice of solid support is important when low ratios of 'liquid' phase to solid support are considered. The use of a solid support having a large surface area per unit weight, such as 'Celite', is not particularly suitable in some respects, since treatment with the 'liquid' phase could leave much of the surface area uncoated, allowing the solid support to act as an absorbent and thus to interfere with the distribution of the analysis sample between the 'carrier' gas and the liquid phase.

Bohemen and Purnell ${ }^{4}$ have discussed the requirements of an efficient solid support. These authors have shown that, as predicted by the van Deemter, Zuiderweg and Klinkenberg rate equation ${ }^{5}$, high column efficiencies are attained when the columns have the following characteristics: $(a)$ narrow range of particle sizes; $(b)$ spherical shape of particle; (c) small quantity of 'liquid' phase. 